DOI: http://doi.org/10.4038/agrieast.v12i2.56

\title{
Role of Colocasia esculenta in Constructed Wetlands for Treating Rice mill Wastewater
} Balachandran, T1 , Nanthakumaran, A 1*, Devaisy, S1 and Sivanesan, K.S ${ }^{2}$

\author{
${ }^{1}$ Department of Bio-Science, Faculty of Applied Science, Vavuniya Campus of the University of Jaffna
}

2 Central Environmental Authority, Northern Provincial Office, Kilinochchi

\begin{abstract}
This study was conducted to assess the efficiency of aquatic macrophyte - Colocasia esculenta to treat the rice mill wastewater especially for (suspended and dissolved) solids, organics, and nutrients in a pilot scale vertical subsurface flow constructed wetlands. Two units of constructed wetlands were assembled with growing media comprised of three layers (soil-sand-gravel), one as control (without macrophyte) and the second as experimental unit (with macrophyte). The collected inlet and outlet samples were analyzed for various water quality parameters and statistical analysis was done to study the significance of Colocasia esculenta in wastewater treatment. The results revealed that Colocasia esculenta was effective in reducing suspended solids $(34.5 \% \pm 15.9), B O D_{5}(53.0 \% \pm 5.7), C O D$ $(50.3 \% \pm 11.1)$, nitrate $(55.7 \% \pm 13.5)$ and phosphate $(76.1 \% \pm 20.5)$ from the wastewater. Besides this, the growing media itself significantly reduced suspended and dissolved solids through sedimentation. Authors claim the Colocasia esculenta was observed to be efficient in treating rice mill wastewater compared to Canna indica for the same experimental conditions. In addition, long term operation of this experiment is needed to study the interactive role of microorganisms to make the treatment system highly efficient, cost effective and sustainable.
\end{abstract}

Keywords: Constructed wetlands, macrophyte, rice mill, wastewater, water quality

\section{Introduction}

Rice is the staple food of Sri Lanka and rice milling is the process of involving the removal of husk and part of bran from paddy. The basic processes involved with the rice milling operations are soaking, steaming, drying and milling. Parboiled rice production generally requires huge amount of water (around 1.3 times weight of paddy) for soaking process. The effluent produced from the soaking process contained high load of organics, suspended solids, fibers etc. (Saini et al, 2016; Paul et al. 2015).

Vavuniya in the Northern Sri Lanka is the agricultural area where paddy cultivation is predominant. This has resulted to the emergence of number of rice mills in the Vavuniya Urban area. The effluent discharged by such rice mills contained high load of organics is directly being emptied into the Vavuniya tank which served as an ecological hotspot for local community in terms of inland fisheries, farming, replenishing groundwater aquifer (Paul et al. 2015). The prolonged practice of discharging rice mill effluent into the tank caused algal blooms and eutrophication and ultimately lost its ecological significance (Dutta et al. 2015). Therefore, having a proper cost-effective, sustainable treatment system for treating rice mill effluents becomes mandatory to ensure environmental safety.

In this milieu, constructed wetland was widely used to remove organics primarily through phytoremediation techniques using various macrophytes and these were found to be efficient, economically viable, technically feasible and sustainable (Mukherjee et al., 2015) compared to conventional water treatment plants (Lee et al., 2009). Researchers had studied the
Corresponding author: n_ananthi@hotmail.com

Received: 08.07.2018 https:/ / orcid.org/0000-0003-0224-3957

Accepted: 06.08.2018 
efficiency of Colocasia esculenta in wetlands for the removal of heavy metals (MaderaParra et al., 2015; Chayapan et al., 2015), nutrients (Bindu et al., 2008), xenobiotics (Cheng et al., 2002), and for treating domestic wastewaters in anaerobic condition (Mbuligwe, 2004) however, the particular macrophyte had not yet been studied for treating rice mill effluent. Considering the better performance of the said macrophyte in other applications, Colocasia esculenta was chosen as a macrophyte in the pilot scale vertical subsurface flow constructed wetland to treat rice mill effluent. Therefore, the aim of this study was to assess the role and efficiency of Colocasia esculenta in reducing organics, solids and nutrients from rice mill wastewater in pilot scale constructed wetland systems.

\section{Materials and Methods}

Feed water: Wastewater produced by a rice mill was used as feed water for this experiment.

Aquatic macrophyte: Healthy-looking nine young plants of Colocasia esculenta (Taro) was used as aquatic macrophyte in the constructed wetland for this experiment. As this is a native species to Sri Lanka this is abundant locally. Further, the qualities such as tolerant to local weather conditions and varying water quality parameters even with toxic elements favored the use of it in constructed wetlands (Madera-Parra et al. 2015).

Experimental setup: Pilot scale vertical subsurface flow constructed wetland with and without macrophytes were studied. As shown in Figure 1, the experimental setup was assembled using a clean cylindrical plastic bucket where an outlet was placed at the wall of the bucket at 6 $\mathrm{cm}$ from the bottom using a ' $\mathrm{T}$ ' shaped PVC pipe. The surface of the wetland media was one square meter. Macrophyte growing media was prepared in three layers consist of gravel, sand and garden soil from the bottom respectively, each placed for $10 \mathrm{~cm}$ height. The size of the gravel and sand were nearly in the range of $5-10 \mathrm{~mm}$ and $0.2-0.5 \mathrm{~mm}$ respectively. This media was thoroughly washed with deionized water to remove contaminants prior to its usage in the wetland system. Then, the macrophyte Colocasia esculenta was planted in the growing media with the plant density of nine plants per square meter. A unit of control system was assembled with same features without macrophyte. The said macrophyte was acclimatized with the feed water for 2 weeks for its better survival in the new environment. The experiments were conducted under controlled conditions in natural environment exposed to sunlight. Once the macrophyte was acclimatized with the feed water, it was fed with $15 \mathrm{~L}$ of wastewater from the top of the media with the hydraulic retention time (HRT) of 4 days. This experiment was conducted continuously for 60 days.

Water sampling and analysis: A grab sampling technique was used to collect wastewater sample from wastewater storage tanks where they store the wastewater prior to final discharge. Before sampling, wastewater was thoroughly mixed with spade to make sure a homogenous mixture. Samples were collected in regular intervals i.e., every 4 days and analyzed for various physico chemical parameters such as $\mathrm{pH}$, Electric conductivity (EC), Total solids (TS), Total suspended solids (TSS), Total dissolved solids (TDS), Biological oxygen demand (BOD), Chemical oxygen demand (COD), nitrate, phosphate, and sulphate.

$\mathrm{pH}$ and EC were analyzed using handheld meters (Eutech instruments, Ecoscan); the TS, TSS and TDS were measured by gravimetric method; BOD by Winkler's method of titration; COD was determined by oxidation $\left(\mathrm{K}_{2} \mathrm{CrO}_{4}\right)$ and titrimetric method. Phosphate, Nitrate and Sulphate were measured by colorimetric method at 
spectrophotometer wavelength $840 \mathrm{~nm}$, $420 \mathrm{~nm}$, and $420 \mathrm{~nm}$ respectively. The standard analytical methods recommended by APHA (1989) were adapted.
The laboratory data was analyzed on Statistical package Minitab version 17 where 'Two sample t-test' was employed to study the significant difference between the means of two groups at significance level of $5 \%$.

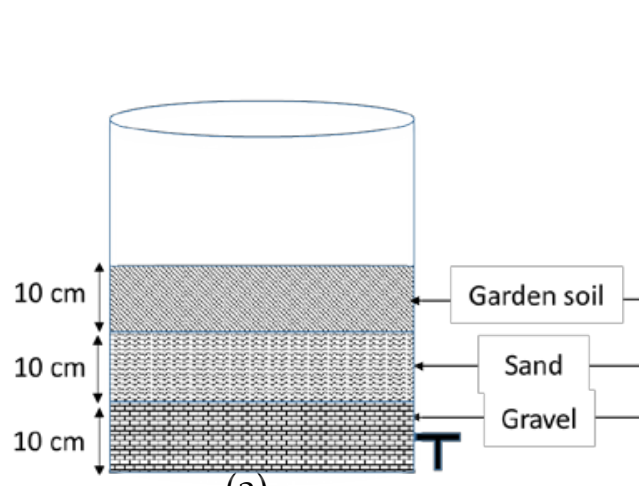

(a)

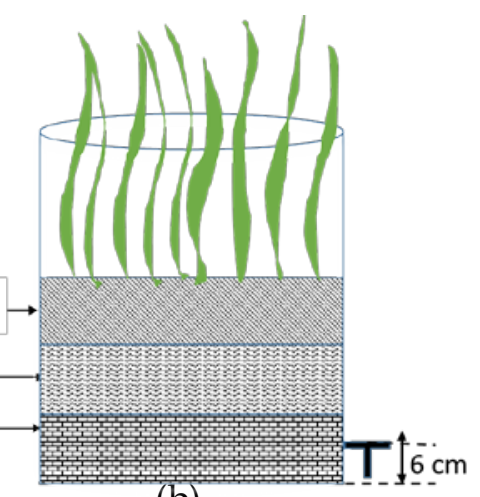

(b)

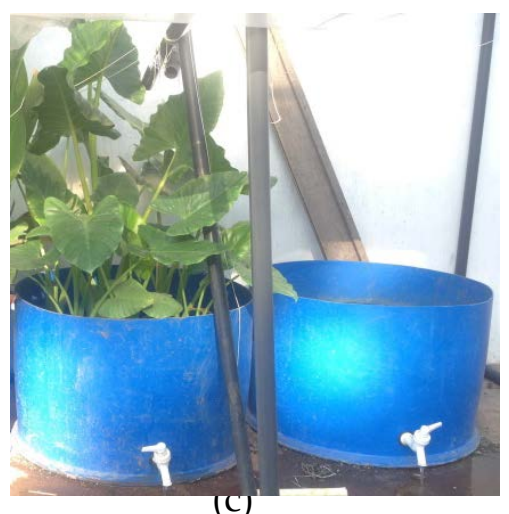

(c)

Fig. 1. Pilot scale vertical sub-surface flow constructed wetlands (a) schematic diagram of control (b) schematic diagram of experiment (c) real experiments both control and experiment

\section{Results and Discussion}

Characterization of wastewater: The wastewater sample collected from a rice mill was characterized for various water quality parameters (Table 1). The $\mathrm{pH}$ of the wastewater was nearly neutral. Based on the organic content, the waste water was characterized as 'high strength' as the parameters were above the critical level (TSS > 400; TS > 1230; $\mathrm{BOD}_{5}>350$; COD > $500)$. Further, the BOD/COD ratio is 0.42 \pm 0.04 indicates the wastewater could be moderately biologically treatable as it lies in between 0.3 - 0.5 (Metcaff and Eddy, 2004).

Table 1. Characterization of wastewater

\begin{tabular}{lll}
\hline Parameters & \multicolumn{1}{c}{ Unit } & \multicolumn{1}{c}{ Values } \\
\hline $\mathrm{pH}$ & - & $6.0 \pm 0.8$ \\
\hline $\mathrm{EC}$ & $\mathrm{mS} / \mathrm{cm}$ & $1.8 \pm 0.3$ \\
\hline $\mathrm{TS}$ & $\mathrm{ppm}$ & $2651 \pm 320$ \\
\hline $\mathrm{TSS}$ & $\mathrm{ppm}$ & $855 \pm 129$ \\
\hline $\mathrm{TDS}$ & $\mathrm{ppm}$ & $1796 \pm 229$ \\
\hline $\mathrm{BOD}_{5}$ & $\mathrm{ppm}$ & $969 \pm 195$ \\
\hline COD & $\mathrm{ppm}$ & $2340 \pm 490$ \\
\hline nitrate & $\mathrm{ppm}$ & $1.2 \pm 0.2$ \\
\hline phosphate & $\mathrm{Ppm}$ & $3.7 \pm 1.5$ \\
\hline sulphate & $\mathrm{Ppm}$ & $44.8 \pm 10.3$ \\
\hline
\end{tabular}

\section{Removal of solids}

The wastewater consisted of huge amount organic and inorganics in the form of settleable, suspended and dissolved solids which was represented by TS in the range of 2058 - 3015 ppm during the period of study. TSS determined in this study represented both settleable and suspended solids that was in the range of 613 - 1105 ppm, whilst TDS ranging 1345 - 2063 ppm. As shown in Figure 2(a), the macrophyte and control media were found to be reducing the TSS remarkably, in which both the control (P-value $<0.05)$ and macrophyte $(\mathrm{P}$ value $<0.05)$ significantly removed the TSS from the wastewater at significance level of 0.05 . This indicates the settleable and suspended organic and inorganic solids were reduced from the wastewater as the water passed through growing media layers as well as trapped and uptake by plant roots. The reduction of suspended particles by growing media was supported by Manios et al (2003).

Considering the removal of TDS, the both systems - control and macrophyte failed 
to remove significantly, however the combined effect of macrophyte and the growing media was found to be reducing the TDS level significantly (P-value $<0.05$ ) from the wastewater (Figure 2(b)). The insignificant removal could be due to the

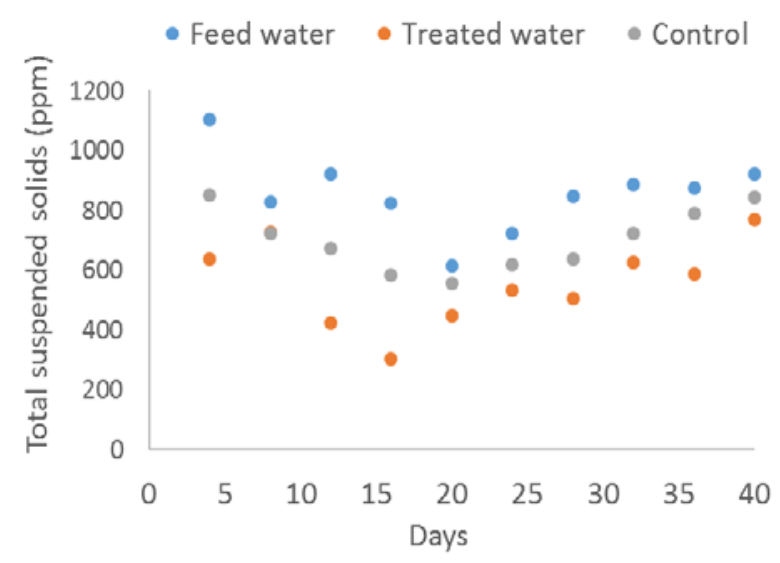

(a) insufficient development of rhizospheres in the root zone due to short duration of experiment as the constituents in TDS generally removed by plant uptake and microbial transformation.

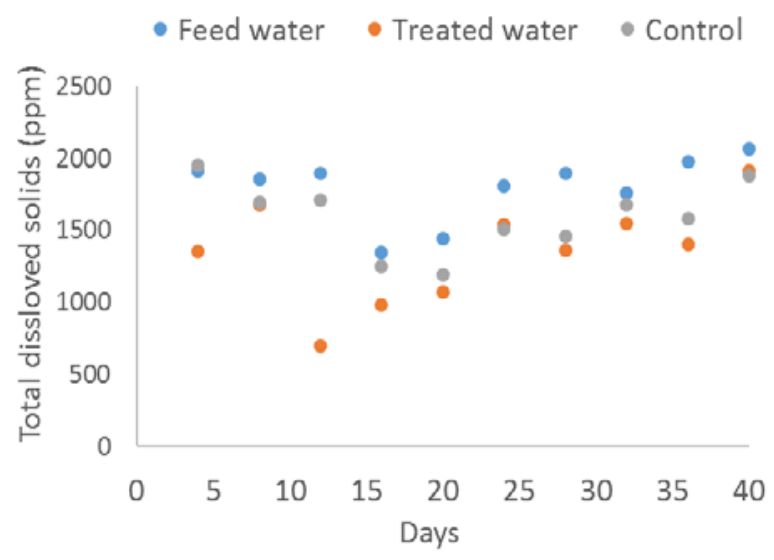

(b)

Fig. 2. Temporal change in the removal of solids (a) Removal of total suspended solids (b) Removal of total dissolved solids

\section{Reduction of oxygen demanding wastes}

The rice mill wastewater contains high load of organics which were oxygen demanding and these increased the level of $\mathrm{BOD}_{5}$ and $\mathrm{COD}$ in wastewater. The fraction of biodegradable organics was indicated by $\mathrm{BOD}_{5}$, and the sum of biodegradable and non-biodegradable were indicated by COD. Since the $\mathrm{BOD} / \mathrm{COD}$ ratio was less than 0.5 , the wastewater was moderately biodegradable as such it might contain both biodegradable and nonbiodegradable compounds in certain level.

As shown in Figure 3, there was a reduction in both BOD and COD level in the effluent after treating through macrophyte and control. It was statistically proven, that both macrophyte (P-value < 0.05) and control (P-value < $0.05)$ had a significant impact on reducing $\mathrm{BOD}_{5}$ from the wastewater (Figure 3a). Macrophyte removed oxygen demanding wastes via plant uptake, increasing aeration and sequent aerobic degradation of organics, and by attached microbial community whist the control reduced such wastes by sedimentation and interception. The reduction of BOD by macrophytes were also reported in previous studies (Shah et al. 2014 and Mazumder. 2013).

The COD also showed the similar trend (Figure $3 b$ ) and both macrophyte (P-value $<0.05$ ) and control (P-value < 0.05) had a significant impact on reducing COD level from the wastewater. As the BOD/COD ratio was less than 0.5 , the wastewater may contain certain amount of nonbiodegradables which could be taken up by macrophytes, and it was supported by (Vymazal. 2011; Abdelhakeem et al. 2016) Further, the compounds contributed to COD may have been removed by growing media via sedimentation. 

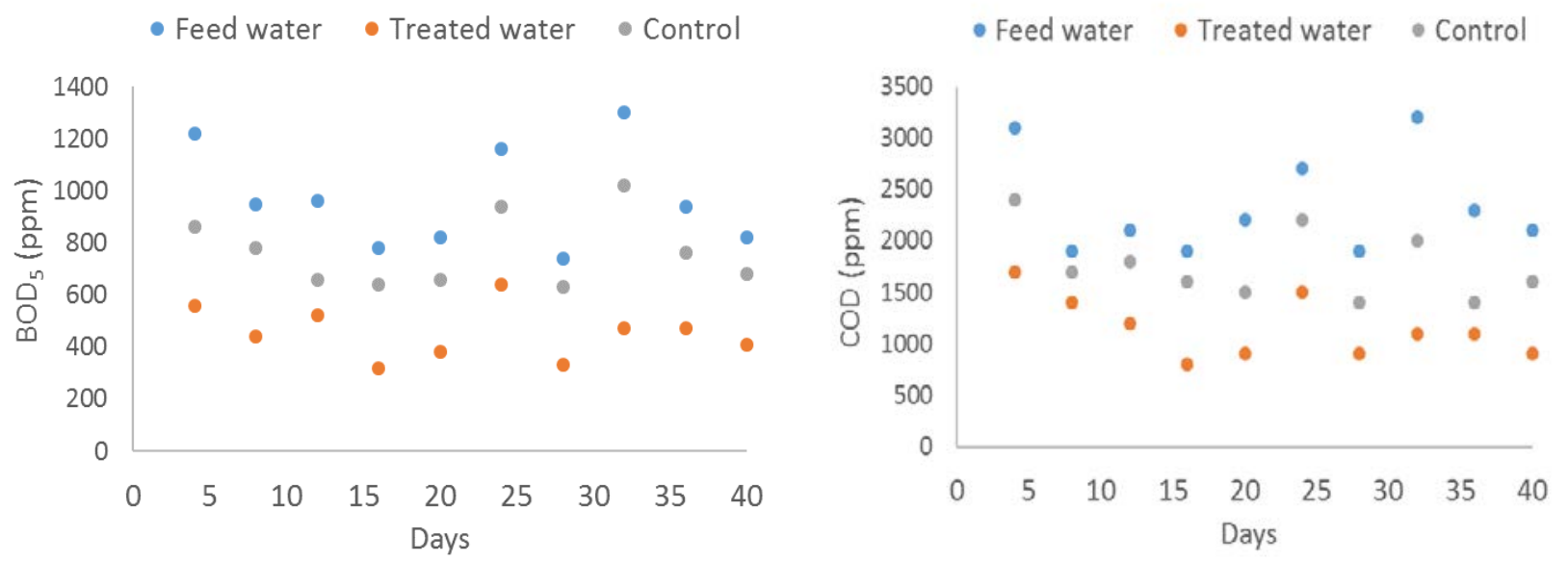

Fig. 3 Temporal change in organics removal (a) Removal of $\mathrm{BOD}_{5}(\mathrm{~b})$ Removal of COD

\section{Removal of nutrients}

The removal of nutrients is important in water treatment as it might cause algal blooms and associated eutrophication effects in adjacent water bodies. Nitrogen and phosphorus were important plant nutrients hence vegetation could uptake nutrients through their root system and stored in tissues (Vymazal. 2011). Thus, the treatment through constructed wetlands is an ideal option to reduce nutrients. As illustrated in Figure 4(a), the macrophyte had significantly reduced the level of Nitrate $(P$-value < 0.05) from the wastewater. The nitrate removal mechanism could be manifold, however in this context, the primary removal of nitrate may have been due to plant uptake as it had short experimental duration to develop more microbial community. The similar phenomenon was reported by Bindu et al. (2008). The removal of Nitrate by the control was noticed to be insignificant (P-value $>0.05)$.

The removal of Phosphorus (Figure $4 b$ ) also was found to be significant by the macrophyte (P-value < 0.05), this reduction might have been primarily due to plant uptake and the similar phenomenon had been reported by Vymazal (2004). The removal efficiency of phosphate was in the range of $41-99 \%$ which was the highest among other parameters analyzed. The removal of phosphate by the control also found to be significant (P-value < 0.05). This phenomenon had been reported by Matikka and Heinonen-Tanski (2016), however, basic idea on the presence of aluminum ( $\mathrm{Al})$, calcium $(\mathrm{Ca})$ and iron $(\mathrm{Fe})$ in wastewater was needed to explain the Phosphorus removal mechanism (Karczmarczyk and Renman 2011).

The macrophyte Colocasia esculenta was found to be the better option in reducing most of the water quality parameters to certain level. It had been noticed the growing media comprised of soil-sandgravel also significantly reducing total solids - suspended and dissolved and oxygen demanding wastes through the processes of sedimentation and interception. As illustrated in Table 2, the removal efficiencies of water quality parameters by Colocasia esculenta was in the range of $24-76 \%$ whilst the control growing media was ranging $11-36 \%$. Authors claim the macrophyte Colocasia esculenta was found to be better performing than the Canna indica which was previously tested with same experimental conditions for same feed water quality parameters (Balachandran and Nanthakumaran,

2017) 


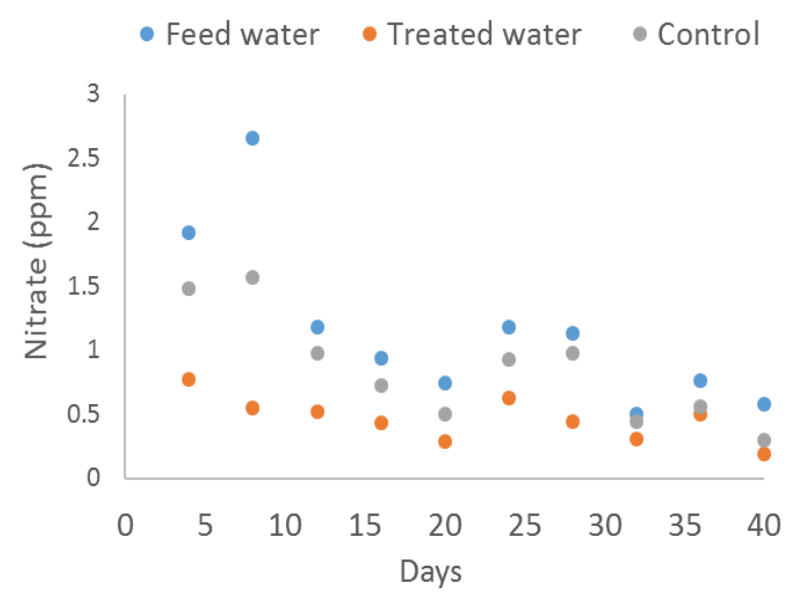

(a)

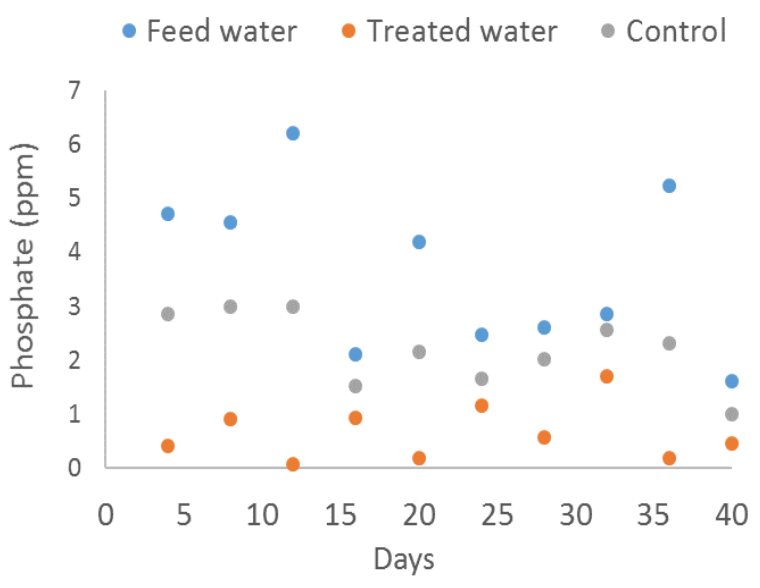

(b)

Fig. 4. Temporal change in nutrients (a) Nitrates (b) Phosphates

Table 2. Removal efficiencies (\%) of experimental (Colocasia esculenta in constructed wetlands) and control

\begin{tabular}{lll}
\hline Parameters & $\begin{array}{l}\text { Experimental } \\
\text { (Colocasia } \\
\text { esculenta } \\
\text { in wetland) }\end{array}$ & Control \\
\hline TS & $27.1 \pm 13.1$ & $13.8 \pm 5$ \\
\hline TSS & $34.5 \pm 15.9$ & $17.7 \pm 7.8$ \\
\hline TDS & $24.7 \pm 16.1$ & $11.5 \pm 7.7$ \\
\hline BOD & $53.0 \pm 5.7$ & $20.8 \pm 5.4$ \\
\hline COD & $50.3 \pm 11.1$ & $24.0 \pm 9.7$ \\
\hline Nitrate & $55.7 \pm 13.4$ & $25.8 \pm 11.7$ \\
\hline Phosphate & $76.1 \pm 20.5$ & $36.2 \pm 13.8$ \\
\hline
\end{tabular}

\section{Conclusion}

The wastewater discharged by the rice mill was characterized as 'high strength' primarily in terms of the presence of high load of organics. The macrophyte Colocasia esculenta was found to be significantly reducing organics especially oxygen demanding wastes, and nutrients from the rice mill effluent. The Colocasia esculenta in constructed wetlands reduced the levels of TSS, $\mathrm{BOD}_{5}, \mathrm{COD}$, Nitrate and Phosphate and their removal efficiencies were in the range of $12.4-63.3 \%, 44.8-$ $63.8 \%, 26.3-65.6 \%, 34.2-79.3 \%$, and 40.8 $98.7 \%$ respectively. However, the control also observed to be significantly reduced
TSS (represents settleable and suspended particles), TDS, $\mathrm{BOD}_{5}, \mathrm{COD}$ and Phosphate from the wastewater and the removal efficiencies were in the ranges of $8.3-29.3 \%, 0-22.8 \%, 14.9-31.3 \%, 10.5-$ $39.1 \%$, and $10.8-56.0 \%$ respectively. In this context, the growing media comprised of soil-sand-gravel function as 'sand filter' and reduced solids, settleable organics and inorganics, nutrients from the wastewater through sedimentation and interception. Therefore, it can be concluded the constructed wetlands and growing media reduced some constituents from the rice mill wastewater and the macrophyte Colocasia esculenta has added advantage over the constructed wetlands in treating rice mill wastewater. Therefore, Colacasia esculenta in constructed wetland has found to be technically effective and economically viable option in treating the effluent discharged by rice mills.

\section{Future study}

The experimental period of this study is not sufficient to develop microbial community in the root zone of macrophytes as well as on the growing media. Therefore, future studies should focus on long term experiments to develop and to interact microbial community with the macrophytes and 
growing media to enhance the removal potential of such water quality parameters to improve the efficiency of the constructed wetland systems. This can be used as onsite water treatment facility at rice mills prior to its discharge into the environment.

\section{References}

Abdelhakeem, S. G., Aboulroos, S. A., Kamel, M. M. (2016). Performance of a vertical subsurface flow constructed wetland under different operational conditions. Journal of Advanced Research 7 (5): $803-14$.

Asati, S. R. (2013). Treatment of wastewater from parboiled rice mill unit by coagulation/flocculation. International Journal of Life sciences biotechnology and pharma research 2 (3): 264-77.

Balachandran, T., Nanthakumaran, A. (2017). Investigation of the potential removal of pollutants from rice mill wastewater by Canna Indica through Vertical subsurface flow constructed wetland. Proceedings of the Vavuniya Campus International Research Symposium $9^{\text {th }}$ August, 2017, 16.

Bindu, T., Sylas, V. P., Mahesh, M., Rakesh, P. S., Ramasamy, E. V. (2008). Pollutant removal from domestic wastewater with Taro (Colocasia esculenta) planted in a subsurface flow system. Ecological Engineering 33 (1): 68-82.

Chayapan, P., Kruatrachue, M., Meetam, M., Pokethitiyook. (2015). Phytoremediation potential of $\mathrm{Cd}$ and $\mathrm{Zn}$ by wetland plants Colocasia esculenta L. Schott., Cyperus malaccensis Lam., and Typha angustifolia L. grown in hydroponics. Journal of Environmental Biology 36: 1179-83.

Cheng, S., Vidakovic-Cifrek, Ž., Grosse, W., Karrenbrock, F. (2002). Xenobiotics removal from polluted water by a multifunctional constructed wetland. Chemosphere 48 (4): 415-8.
Dutta, A., Gupta, S., Mondal, N. K. (2015). Agricultural application of rice mill wastes as a substitution of potash fertilizer in potato (Solanum tuberosum) cultivation. Global Journal of Engineering Science and Research Management 2 (12): 8798.

Karczmarczyk, A., Renman, G. (2011). Phosphorus accumulation pattern in a subsurface constructed wetland treating residential wastewater. Water 3 (1): 146-56.

Lee, G., Fletcher, T. D., Sun, G. (2009). Review: Nitrogen removal in constructed wetland systems. Engineering in Life Sciences 9 (1): 11-22.

Madera-Parra, C. A., Peña-Salamanca, E. J., Peña, M. R., Rousseau, D. P. L., Lens, P. N. L. (2015). Phytoremediation of Landfill Leachate with Colocasia esculenta, Gynerum sagittatum and Heliconia psittacorum in Constructed Wetlands. International Journal of Phytoremediation, 17 (1): 16-24.

Manios, T., Stentiford, E. I., Millner, P. (2003) Removal of Total Suspended Solids from Wastewater in Constructed Horizontal Flow Subsurface Wetlands. Journal of Environmental Science and Health 38 (6): 1073-85.

Matikka, V., and Heinonen-Tanski, H. (2016). Reduction of phosphorus, nitrogen and microorganisms in pilot scale sand filter eds containing biotite treating primary wastewater. Environmental Technology 37 (1): 46-54.

Mazumder, D. (2013). Scope of BOD, Nitrogen and Phosphorous Removal through Plant-Soil Interaction in the Wetland. International Journal of Environmental and Ecological Engineering 7 (2): 104-113.

Mbuligwe, S. E. (2004) Comparative effectiveness of engineered wetland systems in the treatment of anaerobically pre-treated domestic wastewater. Ecological Engineering 23 (4-5): 269-284. 
Metcalf \& Eddy. (2014). Wastewater Engineering: Treatment and Resource Recovery (5th ed.). McGraw-Hill, New York.

Mukherjee, B., Majumdar, M., Gangopadhyay, A., Chakraborty, S. and Chaterjee, D. (2015). Phytoremediation of Parboiled Rice Mill Wastewater Using Water Lettuce (Pistia Stratiotes). International Journal of Phytoremediation 17 (7): 651-6.

Paul, J., Abhijith, D., Arjun Raj, V.R., Joy, J., Latheef, S. (2015). Environmental Impact of Rice mills on groundwater and surface water. International Journal of Civil and Structural Engineering Research 3: 11-5.

Saini, J. K., Saini, A., Lohchab. (2016). Ricemill wastewater treatment by upflow anaerobic sludge blanket reactor. International journal of plant, animal and environmental Sciences 6 (3). DOI: http://dx.doi.org/10.21276/ijpaes

Shah, M., Hashmi, H. N., Ali, A., Ghumman, A. R. (2014). Performance assessment of aquatic macrophytes for treatment of municipal wastewater. Journal of Environmental Health Science and Engineering 2014 12:106.

Vymazal, J. (2004). Removal of Phosphorus in Constructed Wetlands with Horizontal Sub-Surface Flow in the Czech Republic. In: Wieder R.K., Novák M., Vile M.A. (eds) Biogeochemical Investigations of Terrestrial, Freshwater, and Wetland Ecosystems across the Globe. Springer, Dordrecht 